\title{
Using Parallel Texts to Teach Literary Appreciation and Academic Writing Skills of M.A. Students
}

\author{
Anand Mahanand \\ EFL University, Hyderabad, India, anand@efluniversity.ac.in, https://orcid.org/oooo-ooo1-
}

6069-097X

\begin{abstract}
In this paper I would like to report a study I have undertaken to understand whether using parallel texts would be helpful in developing literary appreciation and writing skills of M.A students. I would like to report how I got the idea to use the parallel texts, the way I collected materials and taught them for literary appreciation and writing skills following a bilingual approach. I would also like to share the outcome of my study. A group of ten students participated in the study. The students not only developed in writing skills and literary appreciation but the use of a bilingual approach gave them a sense of pride and confidence that they could use the resources available in their first language in the class and for academic set up at the university level. They were able to write good academic essays with appropriate format and structure. It also prompted them to explore more on the resources they have in their first languages. The paper suggests that such a bilingual approach helps students from rural areas and non-English medium background and who initially experience handicap in their class to cope with their studies.
\end{abstract}

Keywords: parallel texts, bilingual approach, literary appreciation, academic writing skills, M.A. Students

\section{Introduction}

A parallel text is usually defined as a text placed alongside its translation. Parallel texts are available in many languages. For instance, Tagore's poem Gitanjali is available in Bengali, English and in many other languages across the globe. So the English and Bengali texts plus texts in other languages can be called parallel texts. Robert Lowell's book Imitations is a collection of poems translated from different European languages to English. Tennyson's "Enoch Arden" is available in Odia (one of the Indian languages of India) as "Dasa Naeka." T. S. Eliot's famous poem "The West Land" which has been translated as "Podabhuin" is also available in Odia and in many Indian languages. Munshi Prem Chand's novels are available in Hindi, Urdu and English. Novels of many noted Indian writers like Gopinath Mohanty, C.V. Chalam, U.R. Anathamurthy are available in Indian languages as well as in English translation. Parallel texts may also include texts that have identical themes. For instance, texts like Lord of the Flies, Treasure Island, The Coral Island, have similar theme. Parallel texts are also available in the same language but on the same theme. For instance, there are many poems on London. Google shows "ten best poems" on London. Carol Ann Duffy's Answering Back: Living Poets Reply to the Poetry of the Past is a collection of parallel poems. Here each

\footnotetext{
(C) AesthetixMS 2020. This Open Access article is published under a Creative Commons Attribution Non-Commercial 4.o International License (http://creativecommons.org/licenses/by-nc/4.o/), which permits non-commercial re-use, distribution, and reproduction in any medium, provided the original work is properly cited. For citation use the DOI. For commercial re-use, please contact editor@rupkatha.com.
} 
living poet writes a poem responding to a poem written by an earlier poet. For instance, Dannie Abse responds through his poem "Bluebells" to Walter De la Mare's "Echo." John Donne's "Elegie: To his Mistress Going to Bed" is responded by Owen Sheers through his poem "Elegy: To Her Husband Going to Bed."

\section{Types of Parallel Texts}

Parallel texts can be categorized into four main types.

a. Source and Translated Texts: Example of these are Tagore's Gitanjali in Bengali and English.

b. Theme-based Parallel texts: Two texts on identical theme. Example of this is The Coral Isand and the Treasure Island.

c. Trans-Generic Texts: When a novel is transformed from its original genre and made into a film. E.g. The Hucklberry Finn, The Scarlet Letter.

d. Created Parallel Texts : When a text is abridged, simplified or e-written in another form. For instance, a teacher dramatizes an essay to teach it to the students as the essay is linguistically complex.

I have already discussed Source and Translated Texts and Theme-based Parallel texts above. The third category of parallel texts are Trans- Generic Parallel Texts. I call them Trans-generic parallel texts because one genre is changed into another. In the process of transformation, the film makers can make many changes. For instance, new characters are added, existing characters are and scenes are deleted, and scenes are added. For example, Roland Joffe's adaptation of Nathaniel Hawthorne's The Scarlet Letter uses explicit sex scenes whereas the novel does not have such scenes. Films makers tend to take such liberty as they feel that film is altogether a different genre. But some film makers do work in collaboration with the novelists. For instance, for Harry Porter film series, the director worked in consultation with the author, J.K. Rowling. There are novels made into films. Such texts do offer a lot of opportunity to discuss different aspects present in them. The fourth category can be called Created parallel texts. It includes an original text and its abridged, simplified or modified version. As mentioned above, a teacher can create such texts for the classroom. Among the four types of texts discussed, the source and translated parallel are the most common texts available to us and they offer enormous possibilities of language teaching and learning. Hence, I would like to discuss them in elaborate terms.

\section{Source and Translated Texts: Learners L1 as a Major Resource for L2 Learning}

I have discussed different kinds of parallel texts above. Among such texts, source and translated texts are very popular. Texts that are translated from learners Li are usually known to the learners and this knowledge helps learners a great deal in learning the text 
in L2. Scholars have discussed the advantages of teaching in two languages since 1950s. Lia D. Kamhi-Stein in an article titled " Reading in Two Languages"(2003, 37-51) explains that learners take the help of L1 in reading their L2. She also adds that learners who use their L1 are good achievers in reading. She has also found that learners who have a positive attitude towards their $\mathrm{L} 1$ and use it as a resource perform better in L2 comprehension as opposed to those who view L1 as a problem. Jim Cummins (1983) describes the advantages of a bilingual approach. It helps learners uphold their mother tongue. It also helps them to develop a positive attitude towards L1 and helps learners achieve better in their L2.

Most of the students who enrol in Indian universities are strong in their first language and all of them are bilingual. They are familiar with the written and oral narratives that are available in their languages. It is assumed that using a bilingual approach will benefit such students. It is believed that bilingual education enhances learners cognitive development, enables creative thinking and problem solving. Bilingual education also enhances better academic achievement. Hence educationists around the world advocate bilingual education. It also increases the efficient function of brains. It also improves memory. Because of all these advantages, bilingual education is preferred and prevalent in different forms. India being a multilingual country, English has been taught as a second language. Learners are endowed with the gift of knowing many languages. There has been discussions on different aspects of $\mathrm{Bi} /$ multilingual education and ESL teaching since 1980s. Carlos J. Ovando and Virginia P. Collier's work titled Bilingual and ESL Classrooms: Teaching in Multicultural Contexts (1987) could be one of the earliest works that discussed issues related to English in the bi/multilingual contexts. Other important texts include Ofelia Garcia, Tove Skutnabb-Kangas and Maria E. TorresGuzman's Imagining Multilingual Schools: Languages in Education and Glocalization (2006) and Kathleen Heugh and Tove Skutnabb-Kangas' Multilingual Education Works: From Periphery to the Centre ( 2010). The recent work titled Translanguage, Language, Bilingualism and Education (2014) by Ofelia Garcia and Le Wei also deal with the issues related to using bilingual approach in educational contexts. Use of parallel texts will fall under translanguaging. So bilingualism is largely practiced in educational institutions but in certain contexts, teachers shy away from using bilingual methods. I, however, firmly believe in bi/multilingual education and hence carried out the study as an ongoing research.

Scholars have advocated the use of parallel texts and the advantages of using them. Joanne Collie and Stephen Slater for example, in Literature in the Language Classroom (2007) advocate parallel reading. They state: “ Occasionally, a book's themes can be examined more revealingly or more thoroughly through the medium of other sources: through similar or contrasting short stories, poems, essays, newspaper articles, or critical works "( p.67). Alan Maley and Alan Duff's 's book The inward Ear: Poetry in the Language Classroom (1989), has a number of tasks and activities that use parallel texts. For reference see pages 66-69. R. Amritavalli and others in their Position Paper on English (2006) advocate the use of parallel texts. As they point out: "Within the English class, texts from Indian writing in English (both fiction and non-fiction) are now found, 
as well as translations from Indian languages. But the interaction between English and the other Indian languages need to progress beyond this. Ways need to be explored to read parallel texts in their original languages and in English translations, for example"(p.13).

As I started my search, I could gather some texts published in Hindi and English by the National Book Trust of India. I could also collect many translated versions of Tagore's Gitajali. I got English translation of many Odia poems I had studied as a school student. Colleagues gave me English translation of a few Malayalam and Telugu poems. These were enough for me to prepare tasks and activities for my course I also encouraged my students to find English translation of poems of their language poets. I shall discuss the tasks and classroom interaction at a later stage. Now I would like to discuss the advantages of using parallel texts here.

\section{3.o. The advantages of using parallel texts}

\subsection{Familiarity of theme}

Familiarity of theme and the form will generate interest in the learners. Since they are familiar with the texts in L1, they will be interested to learn a text in L2 that relates to the same theme, setting and surroundings. They will be curious to see how these aspects are presented in English (L2). As a school student, I had got some poems by heart and loved them so much. I was happy to see the English version of those poems now as a teacher. Recently I watched some YouTube clips of those school poems being put to music! I am sure children will enjoy those poems more.

\subsection{Drawing Learners Attention}

Through parallel texts we can draw learners' attention to linguistic as well as cultural differences that can be found in the texts. We can draw learners' attention to meaning, structure, and vocabulary related aspects. Students can also find similarities and differences in the use of literary devices such as use of irony, metaphor, simile and so on.

\subsection{L1 Text as reference material}

While reading a text in L2, students find it difficult to comprehend it as they encounter unfamiliar words. In such a situation, they lose interest and stop reading the text. But if they have a translation side by side, they can fall back on the text in Li and find the meaning of the unfamiliar words and proceed to read. Such scaffolding can be withdrawn as they become self-reliant.

\subsection{Self-reading}

Using parallel texts can facilitate self-reading without depending on the teacher. Learners can find meanings in the text and read them in context. 


\subsection{More difficult text can be introduced to the learners}

Learners find certain texts difficult to read due to linguistic complexities. Using parallel texts will ease the anxiety of the learners and help them in comprehending complex texts. The contexts and linguistic support will help them understand texts easily.

\subsection{Association of ideas}

When learners read a text in their second language, they usually associate with elements they know in their first language. They compare the differences and similarities. This is a good way of reading. Parallel texts provide them this opportunity to find similarities and indifferences and associate ideas. For instance, a child whose first language is Hindi is familiar with the concept of a stanza which is called "chhand" in Hindi. When the child finds a stanza in a poem in English, they can easily associate it with "chhand" and understand it as stanza or a group of lines in a poem. It will be easier for them to understand the concept. It will not be necessary for the teacher to explain the concept afresh. Richard Schmidt (1990) calls the difference or the gap "noticing." According to him learners realize or notice the gap between the two languages. Tasks that can be to be given using parallel texts are:

Asking learners to compare and contrast two texts based on elements such as authors' location, themes of the texts and their treatment, literary devices, the context, setting, style of presentation by the writers and reception of the texts among readers.

Scholars have argued that learners who are strong in their Li can also be strong in their L2 as well. Experts like Robert C. Lado (1957) and C.C. Fries (1945) argue that this transference of the features will ultimately lead to a kind of imposition of Li structures over L2.

R.T. Jimenez, . G.E. Garcia and Pearson (1996) who have used think-aloud protocol and reached to the conclusion that successful secondary L2 readers use strategies particular to their bilingual status. Their observed strategies can be summed up as the following:

a. Mentally translating from one language to the other involving the mental processing of L2 words and phrases.

b. Transferring information in first language to second language and

c. Helping on their knowledge of cognate words.

\section{Some of the Ways of Using Parallel Texts:}

a. Using the source and the translated texts: Students can be asked to use the source and the translated texts and asked to compare the two in terms of the authors' location in terms of time and space and the historical contexts, style of presentation and so on. 
b. Using Full and abridged texts: It is also possible to make students compare a full text with its abridged version. Students will get an opportunity to discover the compressed portions of the full text and how it has been done.

c. Using two different genres on the same theme (e.g., film and fiction): There are many films that are made from novels. For example, The Scarlet Letter, Huckleberry Finn, Pride and Prejudice, Lord of the Flies and $s$ on. It would be interesting to compare the two forms and study the difference.

d. Using response to a genre with same or another genre (e.g., answering back, imitation, parody)

\section{The Study}

The study was conducted at the English and Foreign Languages University, Hyderabad in India among 10 students who were part of the course titled Language through Literature as part of the M.A English program during January April 2020 semester. The course ran for one semester through four months. There were 18 students in the course but out of them only 10 took part in the study. These students were from different countries such as Afghanisthan, Indonesia, Bangladesh and India and were users of different languages including Arabic, Urdu, Hindi, Tamil, Bengali and Bhasha Indonesia. All of them were proud of their literary heritage and languages. A pre-test was conducted to test their skills in literary appreciation and writing skills. The test was for 20 marks. Four sets of criteria were used for the assessment. They included Linguistic analysis-5 marks, Content analysis-5 marks, Interpretation -5 marks and Presentation- 5 marks. They were asked to critically appreciate a poem. Their scripts were assessed by my colleague and not by me to avoid bias. But I took a close look at the scripts for analysis. Their scores were recorded. Their scripts showed that most of them wrote the summary of poem and gave their comments on it. They were not able to analyze the content decoding the linguistic devices used by the writer as well as other aspects like the writer's location, style, point of view and so on. They were also not aware of the structure and conventions of writing an academic assignment. Then they were taught how to appreciate a poem and other pieces of literature for more than three months. They were taught the following aspects of literary appreciation: relating the text to the context, finding the author's location the historical context in which the text was written, analyzing the title, theme, tone and mode of narration, reflection on the literary devices such as metaphors, simile, images, allusions, alliteration, allusion, personification, etc., analyzing the linguistic features, such as lexical elements, syntactical patterns, etc. They analyzed poems, stories and pages from novels on same theme but in two languages and marked the deference in them. Texts that were helpful in teaching literary appreciation were HLB Moody's Literary Appreciation, V.S. Seturaman, C.T. Indra and T. Srirman's Practical Criticism and Guerin, W.L et al.'s A Handbook of Critical Approaches to Literature. Students were given small assignments. They chose to compare writings of writers and wrote on the difference in the texts selected by them. I would like to cite three students' writing as examples. 
Student A wrote comparing the Hindi and English texts of Munshi Premchand's Godan. She compared the Hindi text with two versions of its English translation. This is how she has described the difference in the texts. The last section of her essay has been cited below:

After reading all the three versions, I feel that the original Hindi text by Premchand is the best of the three without a doubt. A brief discussion of the great differences between the texts will show why I feel so.

First of all, very noticeably, the texts differ in their tone of narration. All three texts employ the third person point of view; however, while Premchand's tone is empathetic and deeply involved, the narration in the translations seems distant and detached. Jai Ratan and P. Lal's translation has an objective narrator whose language is very wordy, literary, and pedantic. Premchand's narrator, though more refined than the characters, does not stand in great contrast with them. His tone is warm and understanding. The anonymous translation by Diamond Books has tried its best to emulate Premchand's tone by attempting a near-literal translation of the text. However, it ends up looking odd because such language is uncharacteristic of English.

The vocabulary and grammar are also major points of difference. Premchand's work is accurate in its portrayal of the characters because he successfully catches and shows the particular linguistic and phonetic peculiarities in the speech of villagers and the people who come from a certain social background.

Another quality which sets some characters apart is their inability to pronounce certain words or letters. Many Hindi speakers find it difficult to pronounce consonant clusters like "ksha" or even "sha". Respectively, these often become "cha" or "sa" in speech. For instance, Dhania calls a mirror "seesa" instead of "sheesha". Hori is unable to pronounce"prasad" (gift or fruit, in this context), instead, he says "parsad". Such vocabulary gives a lot of richness and colour to the characters; however, the English versions once again fail to represent this. They could have made the speech of the peasants more distinct by having them use inaccurate vocabulary and grammar, just as Premchand does in the target language-to the classroom.

We may note that the write-up is a very close analysis of the texts discussed by student A. Student B wrote on of Subramanian Bharati's Tamil poem and its English version. She Staes:

Although the poem is available in both Tamil and English, I find the original more appealing than the translated one. This is primarily because the original work captures the raw emotions as Bharathiyar penned it. The translation is not able to reflect these feelings or do justice to the passion with which the poem was written originally and hence, it has not been able to fully capture the essence of the poem. This could however be my own personal bias asI am a Tamilian. Another reason why I prefer the Tamil version is that the language used in the it by Bharathiyaar is, in my opinion, way more artistic and poetic than that used in the translated version by Lekha Murali. 
The translated poem, although not as fine as the original, is important as it helps one understand the difficult vocabulary used in the Tamil version. I do not understand the Tamil version with ease despite being a Tamilian.

Student_B write up too shows in-depth analysis and comparison.

Student C compared two translations of one poem called "Hiroshimayude Orma" or " Heroshima Remmbered" by the renowned Malayalam poet K. Satchidanandan. One English translation was done by Sara Susan Cherian and another was done by the poet himself.

One other difference that I noticed between the original poem and the translated poem was the words that were used to describe the bullfighter and his costume. While in the English translation, the poet uses words like "matador", "tight elegant suit", "bright red cape" [which sounds like the words used while referring to the Spanish bull fighting arena (which is what comes into most people"s minds when they think about bullfighting)], the Malayalam version of the poem contains words like "Kaalapporukaarane [(Bullfighter)]", "Irukiya

Thus, while the translator has done a good job translating his poem from Malayalam to English, I like the Malayalam poem (the original version) much better, because I feel that many of the Malayalam words that have been used by the poet seems to convey much more than what it seems to convey on the surface level; this I feel is not something that the English translation of the poem has been able to achieve. However, it must also be said that in some instances, I preferred the word used in the translation over the word used in the original work. The fact that the translation missed out on a lot of cultural things (which added a special Flavor" to the poem.

All the three pieces written by the students show signs of improvement in literary appreciation and academic writing skills. To supplement the qualitative data, another test which was called post-test was conducted to test their learning in writing and critical appreciation. They were asked to critically appreciate a poem. The total marks for this test was 20. The same criteria was applied for post test as well. Their scripts were evaluated by the same colleague who had evaluated the pre-test scripts. Their scores of pre-test and post-tests were compared. There was a significant improvement in the scores secured by each participants. The following table presents the details.

\begin{tabular}{|l|l|l|l|l|l|}
\hline $\begin{array}{l}\text { S1 } \\
\text { No }\end{array}$ & Participants & $\begin{array}{l}\text { Pre-text } \\
\text { score(20) }\end{array}$ & $\begin{array}{l}\text { Post-test } \\
\text { score(20) }\end{array}$ & Difference & Diff. in \% \\
\hline 1 & A & 12 & 16 & 4 & 40 \\
\hline 2 & B & 13 & 18 & 5 & 50 \\
\hline 3 & C & 10 & 15 & 5 & 50 \\
\hline 4 & D & 11 & 17 & 6 & 60 \\
\hline
\end{tabular}




\begin{tabular}{|l|l|l|l|l|l|}
\hline 5 & E & 13 & 17 & 4 & 40 \\
\hline 6 & F & 14 & 18 & 4 & 40 \\
\hline 7 & G & 12 & 16 & 4 & 40 \\
\hline 8 & H & 12 & 17 & 5 & 50 \\
\hline 9 & I & 13 & 16 & 3 & 30 \\
\hline 10 & J & 12 & 17 & 5 & 50 \\
\hline
\end{tabular}

Figure 1

The average difference is $45 \%$. The learners have gained $45 \%$ from the intervention. In addition to the quantitative data, I would like to present a few responses received from the participants. They are appended in the appendices.

An analysis of their transcripts shows that they are able to analyze a text in detail paying attention to literary devices, images and symbols and also other aspects like the location and point of view of the writer. They were asked to write making comparisons between two writers or parallel texts.

\section{Conclusion and Implications for Teachers}

I have discussed the potential of parallel texts for the classroom. I have also discussed their types and usefulness. Among the four types of parallel texts discussed, source and translated texts are most popular parallel texts than can be used for English language education. I have shown through a study how they were useful for my students. Students who participated in the study showed improvement in writing. Feedback gathered from three students have been appended. They took interest as the texts familiar to them were used. Bilingual approach was used to help students retain their language and heritage and helped them say more about it. This helped students confirm that the resources they are familiar with are also knowledge and can be used in academic contexts. They could produce assignments /essays in appropriate format and structure. It helped them to explore further in their first language and prompted them to translate, write and research further. For the transcripts of the students we gather that they are proud of the texts written in their first language and any distortion of the text is not taken kindly by them. Students who hail from rural areas and from non-English medium background usually "experience handicap" in the class at the university in the initial phase ( Das 2018). Such a bilingual approach may give them confidence and help them do better in their studies. It can be mentioned here that parallel texts are widely available around us. Teachers can make use them. The National Book Trust of India and the Sahitya Akademi are a good sources from teachers can obtain parallel texts for learners. It is also possible for teachers to create parallel texts and encourage students to create. It will not be 
difficult to write a poem based on a source poem. Working on the parallel texts will even be more interesting for the teachers and the learners!

\section{References}

Collie, J.\& S.Slater. (2007). Literature in the Language Classroom: A Resource book of Ideas and Activities. Cambridge: Cambridge University Press.

Cummins, J. (1983). Heritage Language Education: A Literary Review. Ontorio: Ministry of Education.

Das, B. K. A proposal for a bilingual model of language education for India: A talk delivered at EFL University, Hyderabad on 18 April 2018.

Fries, C. (1945). Teaching and learning English as a Foreign language. Ann Arbor: university of Michigan Press.

Jimenez, R.T., G.E. Garcia and P.D. Pearson.(1996). Three children, two languages, and strategic reading: Case studies in bilingual/monolingual reading. American Educational Research Journal . 32.(1), 67-97.

Kamhi-Stein, L. D. (2003). Reading in two languages: How attitudes towards home language and beliefs about reading Affect the behavior of unprepared readers." TESOL Quarterly. 37, (1), 35-71.

Lado, R. (1957). Linguistics Across Cultures. Ann Arbor: University of Michigan Press

Maley, A. \& Duff, A. (1989). The Inward Ear: Poetry in the Language Classroom. Cambridge: CUP.

Position paper. National Focus Group on Teaching of English. Delhi: NCERT, 2006.

Schmidt, R . (1990). The role of consciousness in second language learning." Applied Linguistics, 11, 129-158.

Anand Mahanand is Professor in the Department of Materials Devlopment, Testing and Evaluation, EFL University, Hyderabad, India. His research interests include Materials Development, ESP and Multilingual Education.

\section{Appendices}

FEEDBACK FROM RESPONDENT-A

The different tasks used to teach us helped me to understand and be aware of the different aspects (the context, the point of view, the theme, the style of writing etc) that have to be taken into consideration while analysing a literary text. The tasks helped me push my existing limits, and helped me to improve my ability to express both concrete as well as abstract ideas.

\section{FEEDBACK FROM RESPONDENT-B}

First, I want to tell the fact that before I wasn't be able to analyze texts critically. I had problems in many aspects of the texts like writers, their background and the background of the texts. I didn't know how to teach poems, stories, novels. I also did not know how to engage my learners in the lessons, how to make tasks and activities, even I didn't know 
what the role of literature is in language classroom, how to integrate language skills in literature teaching.

But now, I am very happy to take this course (Language through Literature) because it really helped me to analyze texts. Sir made the class interactive. We were encouraged to look at many aspects of the texts like writers, their background and the background of the texts. Sir also made us to read a lot texts and books regarding literature. Sir asked a lot questions and gave many activities to help us think of different aspects of a text. Through these activities, I could improve my knowledge regarding literature. I got much familiar with many books and texts. Sir gave us poems, stories, novels in the classroom and he divided us into group and asked us to analyze the texts critically. Sir always encouraged all our classmates. Even weak students were able to participate in activities and improve their knowledge.

FEEDBACK FROM RESPONDENT-C

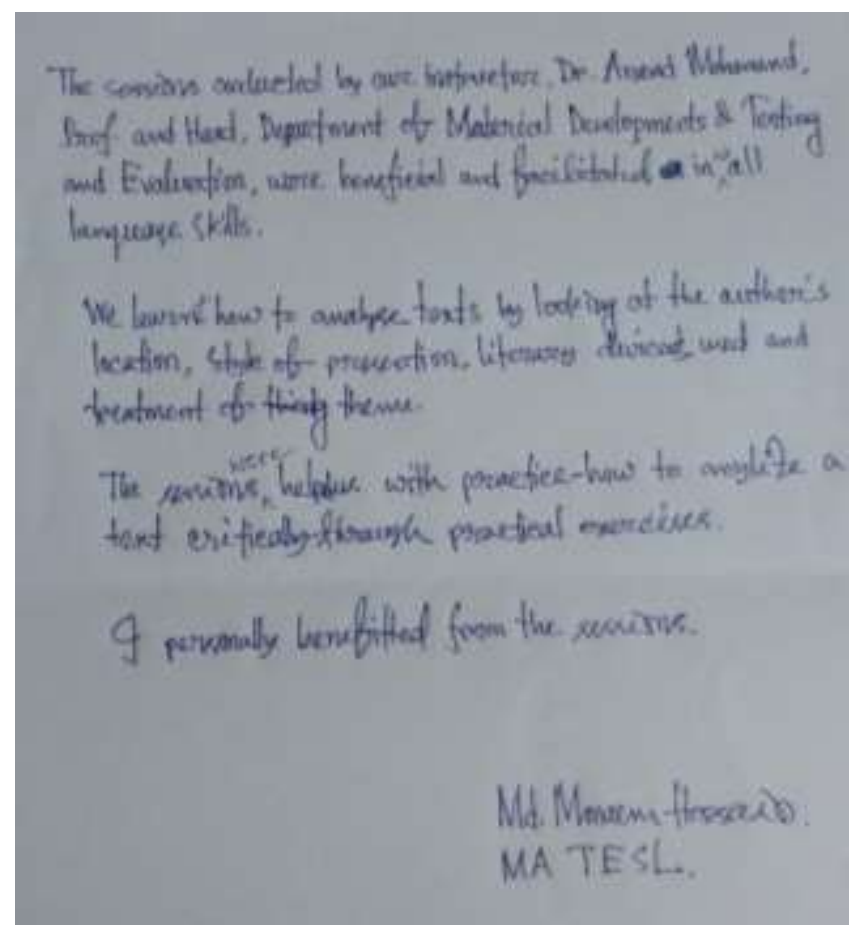

